\title{
Ecosystem-Inspired Enterprise Modelling Framework for Collaborative and Networked Manufacturing Systems
}

\author{
Amjad Fayoumi \\ Computing and Technology \\ Nottingham Trent University \\ Nottingham, Clifton, NG11 8NS, UK \\ amjad.fayoumi@ntu.ac.uk
}

Fayoumi A. (2016). Ecosystem-Inspired Enterprise Modelling Framework for Collaborative and Networked Manufacturing Systems. Computers in Industry, Elsevier, http://dx.doi.org/10.1016/j.compind.2016.04.003

\begin{abstract}
Rapid changes in the open manufacturing environment are imminent due to the increase of customer demand, global competition, and digital fusion. This has exponentially increased both complexity and uncertainty in the manufacturing landscape, creating serious challenges for competitive enterprises. For enterprises to remain competitive, analysing manufacturing activities and designing systems to address emergent needs, in a timely and efficient manner, is understood to be crucial. However, existing analysis and design approaches adopt a narrow diagnostic focus on either managerial or engineering aspects and neglect to consider the holistic complex behaviour of enterprises in a collaborative manufacturing network (CMN). It has been suggested that reflecting upon ecosystem theory may bring a better understanding of how to analyse the CMN. The research presented in this paper draws on a theoretical discussion with aim to demonstrate a facilitating approach to those analysis and design tasks. This approach was later operationalised using enterprise modelling (EM) techniques in a novel, developed framework that enhanced systematic analysis, design, and business-IT alignment. It is expected that this research view is opening a new field of investigation.
\end{abstract}

Keywords: Collaborative manufacturing network (CMN), enterprise modelling (EM), enterprise simulation, ecosystem theory, enterprise analysis and design. 


\section{Introduction}

From the beginning of the Industrial Revolution, manufacturing has experienced a series of changes in paradigm: Quantity of production, cost reduction, quality of production, customisation, lean manufacturing, knowledge- and collaboration-oriented manufacturing, and most recently crowdsourcing and cloud-based manufacturing [1]. The manufacturing environment is usually complex, hard to predict and composed of many interdependent systems, It is also characterised by rapid change and uncertainty, which makes analysing and designing practices rather challenging. Manufacturing value and supply networks in complex socio-economic systems [2, 3] typically show characteristics such as multi-scale interactions with high contingency and nonlinearity, emergent behaviour, pattern formation, and self-organisation. Clearly, the new socio-economic landscape and production techniques have led to increased efficiency, speed, and accuracy; but at the same time, they have increased the complexity of the way companies do and manage business. It is difficult to manage and control these emergent forces and technology on the one hand, and the increasing number of influencing factors on the other; even the most optimistic information and communication technology (ICT) design initiatives have been less than successful in achieving the desired manufacturing and business goals. Complex and nonlinear behaviours entail unfamiliar flows and unexpected sequences; they are mostly not visible or understandable, and are sometimes uncontrollable or uncertain. These kinds of complex behaviours cannot be envisaged by designers, or managed by operators, without extensive modelling and simulation.

In this context, many modelling and simulation approaches were adopted; some influenced by computer science approaches, and some inspired by operations research. Enterprise modelling approaches provide a holistic view of an enterprise's structural, functional, and behavioural aspects, and allow for better operational design, business-IT alignment, and performance measurement. In fact, they also offer a foundation for business and technical development and advancement - although some other approaches were adopted in similar contexts, such as soft system methodology [4], systems thinking [5], and operation simulations [6]. However, these approaches can be advanced by reworking their theoretical and practical use to better fit with the notion of collaborative and networked manufacturing ecosystems.

The research presented in this paper draws on a theoretical discussion and proposes developing a "framework" to better understand the complex and evolvable nature of the collaborative manufacturing network (CMN). The design of this framework takes into consideration the agility and effectiveness of the holistic analysis to design enterprises and their underlying information systems, and suggests practices that support modelling and simulation in the digital era. To this end, this research is founded on connecting the principles underpinning two research domains, namely those of (a) ecosystem theory, and (b) enterprise modelling, and this novel research view opens a new field of investigation. The main research questions this paper aims to answers are:

1. What lessons can we learn from ecosystem theory to better understand the collaborative manufacturing network environment?

2. How can the new understanding be reflected in a practical diagnostic enterprise modelling framework? 
The paper is organised as follows: Section two briefly reviews the current approaches and state of the art in collaborative networked manufacturing analysis and design, and discusses their limitations and the challenges facing CMN enterprises. Section three describes the research methodology used in this paper, and section four discusses the utility of ecosystem theory. Section five reviews and then introduces the enterprise modelling framework in terms of its conceptual perspectives, process, and supportive tools. Finally, section six provides a set of concluding remarks, and recommends a direction for future work.

\section{Challenges Faced by CMN Enterprises}

Traditionally, manufacturing enterprises have a supply chain where suppliers provide raw materials, and distributors offer channels to market and sell products to end customers. As mentioned in the previous section, the current open market economic model is highly demanding, and presents manufacturing enterprises with new challenges. Customers are looking for better services, technology is continuously advancing, and the number of competitors is increasing. To face these challenges, manufacturing enterprises need to work more intelligently, and so they have adopted new business models that address current market conditions more effectively. Strategies such as outsourcing, offshoring, and externalising business activities - especially the secondary and support activities have become more acceptable to every enterprise that wants to modernise its business activities and remain competitive on a global scale. Internet business models have optimised this process, allowing customers to easily buy products directly from the manufacturing company online. Supply agreements can also be easily reached over the Internet. This allows a greater variety of global business options, not only for the end customers, but also for the manufacturing enterprises themselves, transforming the supply chain into a dynamic network. What makes this network dynamic is the agility of its nodes - the ability for any of them to change their relationship and connection to the others, according to market requirements and the level of value created for the enterprise from the other side. Manufacturing enterprises began utilising information systems (ISs) in order to have better control over their activities, offer a better customer experience, and to work collaboratively - with either partners or customers - to produce innovative product designs, increase service quality, and customise and personalise manufacturing services. For example, Montreuil, Frayret and D'Amours [7] introduced the NetMan strategic framework, which considers the decentralised manufacturing activities favoured by the nature of the new open market. As a result of this work, the authors provided significant classification of granularity, responsibilities, capacities, interactions, contracts, and pattern-based design for different network configurations. Lee, Park, Yoon and Park [8] presented a number of innovative business models which go beyond the traditional supply or value chain, where a network of organisations collaborate to generate value in an open innovation model. In their global engineering network (GEN) proposal, the authors suggest five perspectives for investigation $[9,10]$ : 1) Network structure, 2) operations processes, 3) governance systems, 4) support infrastructure, and 5) external relationships. Based on this classification, Zhang and Gregory [11] found that enterprises configure their value chain and operations based on one of three generic drivers: Efficiency, innovation, and flexibility. They go on to propose guidelines for enterprise design compatible with the GEN concept. 
On the information systems side, Montreuil, Frayret and D'Amours [7] suggest that agent-based simulation is required for their developed NetMan framework in order to optimise and predict network behaviour. Wang [12] presents an IS framework to support collaborative manufacturing services which considers interesting technical capabilities such as ontology use (OWL) and semantic software services (WSDL-S). We also can find in [13] an approach to measuring the impact of implementing new "RFID" technology on cost reduction in networked manufacturing; the authors suggest that implementing RFID can improve the overall manufacturing operation and positively influence the total supply chain cost.

Although the previous studies have inspired and helped to formalise emergent thinking in the manufacturing domain, most manufacturing enterprises still optimise their activities locally rather than performing global network optimisation [14]. Also, the manufacturing enterprises in many countries fail to cope with environmental changes, which implies a failure in increasing innovation and service sustainability to a level that lives up to global market demand. This may result in increasing the risk of losing markets, or at minimum losing customer trust.

The final critical issue is related to risks taken during the decision-making process in CMN; since the $\mathrm{CMN}$ is highly dynamic, many decisions need to be made continuously, and changing strategic choices might bring serious risk and losses to different levels of enterprise granularity. Previous literature did not address the alignment issue among theories, practices, tools, and information systems development. Therefore, a systematic and semantic approach using intensive modelling and simulation is required to support decision-making during both enterprise design and operation.

\section{Research Methodology}

The science of design focusses on producing and reproducing artefacts in order to fulfil some human purpose or need. Artefacts are produced, using principles of science and engineering, from either organic objects or previously produced artefacts. Human understanding and comprehension play an important role in defining what the artefacts are, for what purposes they are required, what to use in order to produce said artefacts, and how the artefacts themselves are produced. Design science has recently been widely adopted as a research approach, particularly within information systems and operations research $[15,16]$. This paper is based on the approach presented in [17], which offers a design science framework for theory development in information system researches (DSRIS). The data collection will rely on historical evidence that supports the argument of the paper from the ecosystem principles point of view. Data analysis techniques considered in this research are similar to those suggested in grounded theory research [18], and many of these methods (e.g. data classifying, connecting, comparing, and criticising) contribute to the sense-making process for interpreting CMN system characteristics and behaviours. The most important design science reasoning and analysis practices and techniques are described in [17], such as deduction, induction, abduction, and reflection, all of which are crucial to understanding the theorisation in design science and information systems research. Design-relevant explanatory/predictive theory (DREPT), as suggested in Kuechler and Vaishnavi [17], augments the "how" information content of the traditional information system design theory (ISDT) statement, explaining why the artefact has the effects it does. This explanatory element may borrow theoretical information from the natural, social, or design sciences. DREPT is similar to, 
but more formally stated than, the "justificatory knowledge" proposed as an addition to ISDT. It provides a logical step that bridges the conceptual distance between kernel theory constructs and artefact features.

The resulting diagnostic framework is both an output and part of the design process. "Both the design product and the design process may specify kernel theories, typically defined as "natural science theories from other disciplines' [19] that suggest either the meta requirements or the construction process". In this case, the kernel theory employed during the framework design process was ecosystem theory from the natural sciences. Thus, the historical cases and scenarios led to a novel interpretation that helped to generate new artefacts; specifically, the diagnostic framework for CMN enterprise modelling and simulation as a design result.

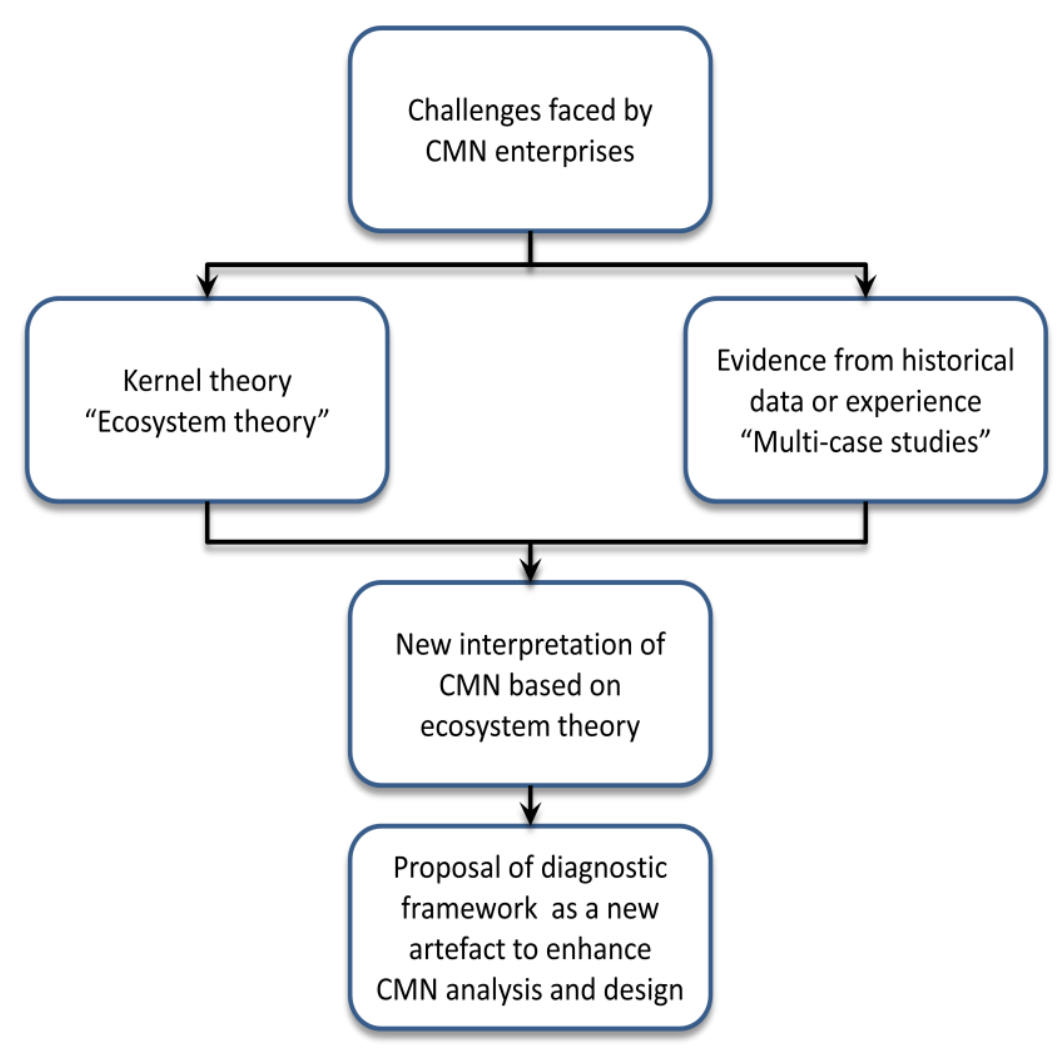

Fig. 1. Research approach.

\section{Exploring Ecosystem Theories}

The analysis of literature on CMN highlights the need for a comprehensive model using a systematic process to analyse and design collaborative networked manufacturing enterprises. The limitations in the current approaches have motivated our work to explore theories of ecosystem domain in order to understand the nature of the organic systems, and the essence of communication and collaborations 
between organisms in such a system. This section provides a short introduction to the domain's influence on our work.

\subsection{Lessons Learned From Ecosystem Theory}

An ecological community is a group of trophically similar, sympatric species that actually or potentially compete in a local area for the same or similar resources. Hubbell presented an explanatory theory that is formulated entirely in terms of chance [20, 21]. Ecosystem theory also relies heavily on a central metaphor, which is that an ecosystem imposes a process through which multiple agents adapt to survive in competition for finite resources. There are some approaches that apply biological and ecological theories to the IT domain [22-24]. Early ecological approaches explored by Fidel [25] "suggests that ... analysis should begin with, and be driven by, an explicit analysis of the constraints that the environment imposes on action". The central reason to focus on environment is because the collective distributed intelligence of the whole system is always greater than the total knowledge of any sole part [25]. The main property of an ecosystem is that it is an environment of distributed heterogeneous organisms or agents in distributed and remote geographical locations, and they inhere in nature to produce a community which has an amount of population [2628]. Many principles of ecology and natural science - such as symbiosis, natural selection, selforganisation, gene duplication and gene robustness - can all be considered as aspects of the evolution of the enterprise socio-technical system. An understanding of such principles can help to clarify the nature of the CMN systems. For example, Yu argues that using gene duplication as a metaphor helps in the design of better enterprises and contributes to their success [23, 24]. All the concepts of ecosystem theory may influence the manufacturing enterprise's product, process, strategy, technical mechanism, performance, and location.

The following draws analogies between the principles found in ecosystems [22] and their counterpart examples from manufacturing enterprises.

Symbiosis: Traditionally, management scientists conceived the manufacturing and supply activities as a chain of tasks and events. Yet the fact is that the manufacturing activities are networked, complex, dynamic, and interrelated; they are based on acceptance and value exchange. Nowadays, manufacturing is a network-based industry, and manufacturing enterprises are elements within a context of business ecosystem interdependencies. Supply and value network activities such as production, delivery, and aftersales services are more likely to be collaborative activities in modern manufacturing enterprises. All can involve subcontracting, offshoring, and outsourcing part of the business model in order to optimise the value network to the maximum and generate profit. The network model is more complex and highly dynamic compared to the simplistic chain view. Thus, it is also important to understand symbiosis types and trending, as symbiosis can take several forms. These models include business to consumer, business to business, business to community, business to government, and business to non-profit organisations. An example of a symbiotic relationship could be seen when Schlumberger partnered with Chinese universities to place their labs within their campuses, allowing the universities to offer their students cutting-edge lab experience in solving realworld problems, while Schlumberger benefited from being able to hire the best graduates of the universities. Another is the partnership between Starbucks and the Indian company Tata, creating a 
joint venture which enabled Starbucks to finally enter the Indian market, whilst Tata's investment of resources and market knowledge was rewarded by a share in the profits of one of the biggest coffeeshop brands in the world. Another model can be found in IT product warehouse partnerships; the reseller is both a dealer and a customer, benefitting from promotion, training, technical support, and advice from the manufacturer, in return for generating more sales by presenting the products to the end customer as part of a proposed solution. Nevertheless, enterprises need to be aware of the impacts and impact levels of the symbiotic relationship, since there are some harmful or detrimental relationship types, which will be discussed later in this section.

Natural selection: Only the best and most robust survive. The environment is able to select the best among alternatives - be they systems, enterprises, products, agents, or groups - to perform specific tasks. An enterprise should deliver good products or services to satisfy valued customers in order to survive; otherwise, it will be eliminated due to market competition. Natural selection is enforced by many internal and external drivers, e.g. customer demand, changes in the economic landscape, skills emigration, habitat, and cultural evolution. For instance, in the 2008 financial crisis, many manufacturing companies were not able to maintain the stability of their manufacturing activities. Even enterprises as large as General Motors declared themselves bankrupt, and the collapse of Lehman Brothers bank is considered the largest bankruptcy filing in U.S. history. Enterprise activities are subject to natural selection; after the joint venture between Starbucks and Tata, Tata have replaced the coffee supplied from the international market with local Indian coffee, which cut logistic costs and supported the local economy whilst still offering high-quality coffee to customer. Disneyland has also announced that a new Asian local supplier will supply to their park in Hong Kong during both construction and operation. This type of business decision can be considered natural selection, as enterprises want the option that best suits their value-creation process. Cost, time, quality, benefit, creativity, brand recognition, increased profit, waste, and environmental friendliness are all drivers of the natural selection process.

Self-organisation: The enterprise's internal activities, strategy, and innovation form their image and brand reputation. The enterprise should have the ability to evolve and adapt with its environment. Self-organisation practices that touch all levels of the enterprise's activities include making changes to business models, organisational structure, management style, product specifications, communication, collaboration, operation optimisation, and technology. For example, Jaguar Land Rover was forced to sell its business units to Tata Motors when they failed to secure a loan of around $\$ 1.5$ billion from the UK government to avoid collapsing after the economic crisis hit Europe. Another form of selforganisation can be found in the case of the IBM corporation, which went through several shifts in their business model to match market demand - from computer manufacturing and design, to software applications, to nowadays focusing on IT and consulting services. Recently, Samsung have decided to focus on producing white goods, with the aim of enriching the smart home concept as they realise the promising potential of this sector. Nokia have failed to maintain their position in the mobile market in the smart phone era, and the only self-organising option left to them was to accept the offer from Microsoft to sell their mobile unit completely. Nokia shifted their focus to developing tablets, while Microsoft used it as an opportunity to enter the mobile market with integrated software, web, and smart phone technology and compete with big players like Google, Apple and Samsung. Enterprises 
can also self-organise based on geographical location; ABB Dubai mainly focusses on renewable energy products and projects for smart and sustainable cities, while in some European countries their range of products and services concentrates on robotics, automation, and green technology.

Gene duplication: Creating or generating an extra copy of the gene may give rise to completely new materials or products which in turn will support the evolutionary process. The manufacturing enterprise aims to create a stable version of a product design which can become a basis for further development and innovation. This can then either add features which fit into new environments, circumstances, or places, or it can re-use the same design within another product that can offer new functionalities or features. On a strategic level, enterprises can establish new divisions, or even new enterprises, that duplicate the original enterprise's business model with a higher proportion of experimental activities, and more agility for targeting new markets and customers. The new version is considered a clean facsimile of the original company, and previous activities have less impact on its image. Adopting such a strategy will drastically reduce strategic and operational costs and risks. There are two types of gene duplication. Firstly, the accidental: Many inventions were discovered inadvertently, such as Velcro, penicillin, anaesthesia, 3M Post-it notes, the microwave, and X-rays. Secondly, the planned: For example, in 2000 Al Safi announced a partnership with Danone, allowing the transfer of expertise and skills, and giving Danone the opportunity to enter the Saudi market with a well-established brand. Al Safi continued producing products under their own brand as well as testing the market with new products under the Al Safi-Danone name. This exploratory period saw a number of products introduced to, and then withdrawn from, the market in line with levels of demand. Another example can be found in Google, when they decided to enter the DARPA Grand Challenge for robotic vehicles in 2004, which led to them evolving a completely new unit concerned with the development of a new, smart, self-driving car. In the automotive industry, Mercedes, Land Rover, and other car manufacturers opened assembly - and some parts-manufacturing - facilities in the Middle East to serve the local market, especially with regards to upgraded specifications that meet the climate and environmental conditions of the region, e.g. air conditioning, engine cooling, air filtration, and localised GPS. Similarly, many IT companies - namely IBM, Microsoft and Oracle - have also established research centres in the Middle East and North Africa to localise their core products and conduct research that concerns local customers. However, other companies have taken a different approach, and have decided to take advantage of the advancement of technology by offering their digital or customised products and services through the internet where possible.

Gene robustness: The buffering of gene changes against environmental disturbance during the evolution processes. There are many examples of design and manufacturing products that have survived decades of industrial and economic changes. Sometimes this is due to the nature of the product itself; on other occasions, it is related to a lack of motivation - or need - to change the current paradigms in designing new products. At the strategic level, genetic robustness is also demonstrated by enterprises that take advantage of the cultural or social systems established in a particular region to operate locally, with no adoption of e-business practices within a traditional organisation and trading structure. Microsoft Windows is a prime example of a robust gene, as it sustains both its market position and its level of user acceptance despite decades of technological changes. Equally, Apple have the robust Apple Mac laptop brand, which has grown over the years despite severe competition 
from other companies producing alternative devices that are attractive in terms of both price and quality. Coca-Cola remains one of the three strongest brands in the world, even after decades of market changes and shifts in consumer trends. Technological robustness is also relevant; electrical and mechanical devices have operated on the same principles since their introduction, with only minor changes stemming from either natural selection or gene duplication. Robustness can also be found in processes, such as Toyota's production system, which has been a benchmark for many other companies across multiple sectors.

As there are characteristics of an ecosystem environment, there are also specific relationships among the agents within an ecosystem, system, or enterprise. The following list gives a summary of such relationships, and provides examples from the manufacturing domain.

Mutualism: Both systems benefit from the relationship. This kind of relationship is considered a goal for each enterprise operating in a collaborative networked environment. Traditional partnerships between two companies (e.g. joint-venture, supplier, sub-contractors, distributor, retailer, and legal advisor) see both companies exchange values. Mutualistic relationships can also exist between two industries or departments, such as the interaction between the IT and production industries or departments.

Commensalism: One system benefits from the relationship, whilst the other is unaffected. Governments have created many services to benefit society, but on examination of each particular project or service it can be difficult to identify the value returned to the government. Most charitable and voluntary work is also characterised by this type of relationship. For example, non-profit national libraries, public parks, and open museums are some examples that benefit the consumer with no specific value returned. In a strategic business partnership, there is also a chance of commensal relations when one partner is learning from the other, and the other is not affected. In the manufacturing industry, there are some incubators that are interested in supporting, advising and assessing manufacturing start-ups and SMEs for free.

Parasitism: One system benefits from the relationship, whilst the other is harmed by it. Service and consulting-style manufacturing organisations are actually parasites on manufacturing companies who offer tangible value to the consumer, so many examples of collaboration among manufacturing companies and private, public, or academic institutes can be classified as "parasitism" in terms of high cost and lack of value delivery. The idea of "efficiency wages", which Henry Ford used to create a huge enterprise in a disruptive technological area, is precisely this sort of "parasitism". In "the fivedollar workday", the wage-effort relation was not balanced and the enterprise paid double salaries to their productive employees, necessitating competitors to do the same in order to not lose their services. Another example of parasitism is the relationship between industry and the natural environment. The natural resources extracted from the environment are returned to it in a harmful form, such as greenhouse gasses, that contribute to increased pollution and global warming. 
Amensalism: One system is harmed by the relationship, whilst the other is unaffected. An example would be government policies and tariffs that influence the business activities of some enterprises. Some governments have established new policies for customer protection or green practices, which don't directly affect the government but put pressure on the enterprise and lower its profits. Humans have an amensal relationship with their environment, which invariably suffers as a result of human activities. For instance, air pollution caused by power generating plants, automobiles, or metal smelters often causes severe damage to lichens and plants in the affected area, whereas humans are not harmed by this activity. Sometimes, joint ventures can be characterised by amensalisim, when a partner company is not able to take advantage of the relationship and learn the core competencies while the other partner suffers due to allocating resources and assets to the joint venture [29]. Also, in some cases, the relationship between non-profit organisations and enterprise might restrict the business while the real benefit goes to third parties like employees. An example of this can be seen when Oxfam put pressure on Nike to improve the welfare and rights of its workers.

Competition: Both systems are harmed by the relationship. While this kind of relationship is unwanted, it is however a necessity in an ecosystem environment. When two systems or agents compete for resources, market or customers, practically they are both harmed until they establish "game rules" as a kind of agreement protocol. If this situation is not arranged, it is possible that one of the systems will be completely eliminated at some point of the competition. For instance, competition between Apple and Samsung took many phases - legal, political, and marketing - to win the biggest market share, while prices were reduced and investment in R\&D increased. In many cases, competitors reach an ethical agreement in order to maintain the prices at a certain level, but this is going to harm a third party - in this case the customer, who is the main beneficiary of a competitive relationship between producers.

Neutralism: Both systems are unaffected by the relationship. This is not attractive for enterprise, but it is sometimes necessary; for instance, the relationship between the enterprise and the local council may not be characterised by value exchange, instead being built to comply with legislation. Some relationships may be enforced by social expectations, protocols, procedures, and codes of practice rather than value exchange. Some neutral relations are planned, such as enterprises starting to adopt green and sustainable practices with the goal of establishing a neutral relationship with the environment by lowering the carbon emissions to a more acceptable level. Figure 2 describes the understanding of collaborative and networked manufacturing from an ecosystems perspective. 


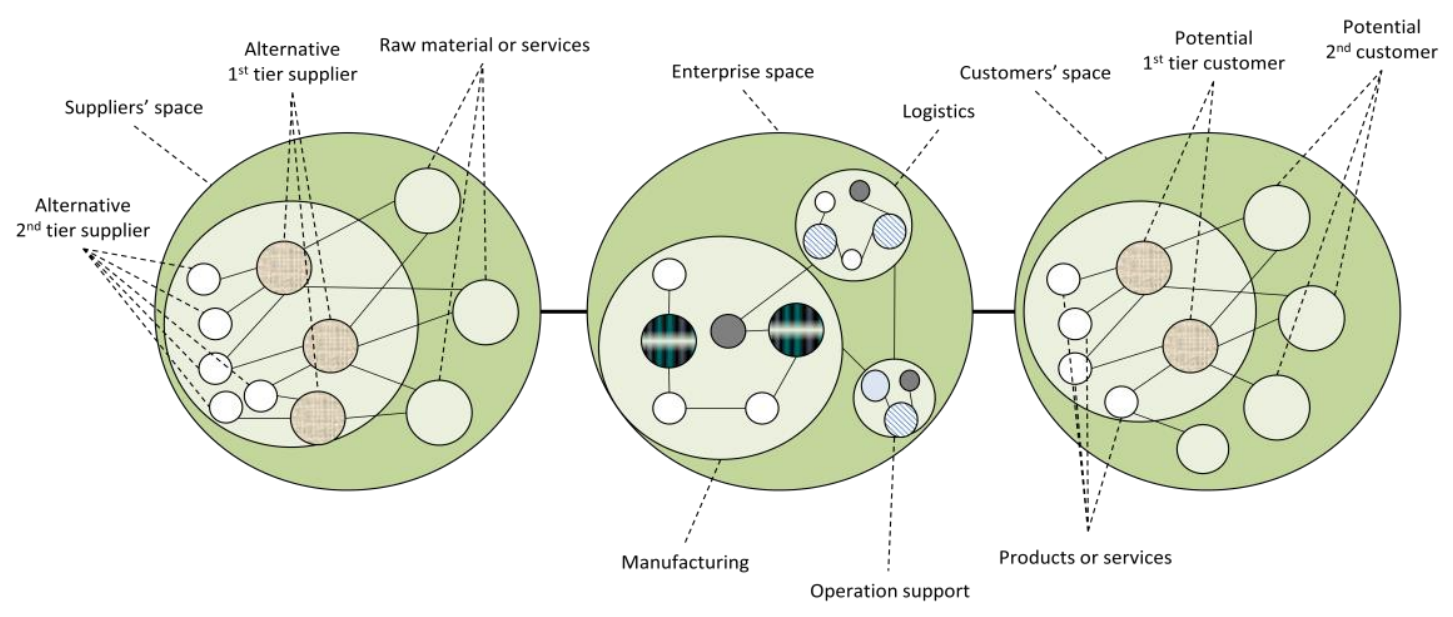

Mutualism: Typically a relationship between the enterprise and the supplier, and the enterprise and the customer Commensalism: For example, the environment benefits from firms that recycle goods and materials after use, but recycling activities do not return value to the enterprise.

Parasitism: The relationship between the supplier of raw materials and the environment, where the supplier drains natural resources to make a profit. Amensalism: The carbon footprint produced by factories harms the environment, but has no immediate negative impact on the factory's profitability. Competition: The typical relationship between two alternative suppliers.

Neutralism: Such a relationship is very difficult to prove in natural and artificial ecosystems. However, temporary neutralism is possible when two systems, companies, departments, machines, or parts are postponed, waiting for some event to trigger interaction, or otherwise passive.

Fig. 2. Collaborative and networked manufacturing ecosystem.

Two understandings emerge from applying ecosystem theory in CMN. Firstly, the planned or unplanned evolution of an organisation must be studied in light of its interactions with its environment. Factors such as skill and capability emigration and new disruptors - like the Internet can fundamentally change the enterprise habitat. Mobile phones, for instance, altered the way people communicate, do business and interact, in addition to initiating new business models. All in all, the new direction of analysis through so-called "ecosystem thinking" is suggested [28] to be highly influenced by the systems thinking approach $[5,30]$. Secondly, considering a CMN as an integrated ecosystem suggests that it is necessary to understand the context in which the CMN is operating. This bottom-up approach advocates looking at interactions based upon the nature of the technical system and developing a method to suit the particular enterprise. Interaction between the enterprise and its context is important in this approach. Enterprise-ecology interaction, enterprise-economy interaction, enterprise-social interaction and enterprise-business trend interaction are all among the issues of concern [31].

Mumford [32] and [31] argue that there is no complete design, and the requirements keep intertwining within the context, causing the design to evolve gradually along with the ecology. Therefore, the ultimate goal of designing new manufacturing systems is to create an autonomic heterogeneous system that can sustain and reconfigure itself $[33,34]$. Research assumptions, and their potential realisation, are based on three ideas. In order to analyse collaborative manufacturing complexity and evolvability, consideration needs to be given to the process of decomposing the manufacturing enterprise system into smaller sub-systems, and the need for those systems to be modular at an abstract level to fit into different degrees of granularity. In the most suitable cases, these will be automatically selected and configured. The enterprise process model should be embedded in the IS and should be mapped to software service components in order to develop and deploy the supportive IS/IT systems. The CMN enterprises have emigrant properties for the whole global manufacturing 
system. It highly depends on the configuration of the networked system nodes as well as on the relationships and dependencies between those nodes, which make the socio-technical properties consistently dynamic and the subject of change.

Nowadays, in the Internet era, some new business models and organisation structures - such as collaborative value networks, networked and open design and innovation, supply networks, global market outsourcing and offshoring - become crucial. Practices such as customer relationship management, social network analysis, global business and economies analysis, consumer behaviour analysis, trend forecasting and resources analysis were developed to support strategic decisionmaking. Such practices become more powerful and more effective in the digital era of Web 2.0 and onward, where a substantial quantity of quality data is available to support business analysis and design. With regard to the supportive technical aspects, work has been proposed in terms of software evolution, particularly in fitness algorithms, evolutionary genetic algorithms, and multi-agent systems $[26,35]$. However, it is important to build upon the theoretical foundation with practices and technology, and therefore an approach for analysis and design based on enterprise modelling will be discussed in the coming sections of this paper.

\section{Enterprise Modelling Framework for CMN Systems}

\subsection{EM Background and Related Work}

Enterprise modelling (EM) is an abstract representation and description of an enterprise's elements and sub-elements. Researchers in the domain approach enterprise modelling from various standpoints, sometimes combining more than one perspective to fulfil enterprise needs. According to [36], EM is the art of externalising enterprise knowledge, which adds value to the enterprise. Enterprise can be a single private, government, networked, virtual, or smart organisation. The aim of using enterprise modelling techniques is to reduce enterprise design complexity, increase coherence, align business and IT, analyse operations, and optimise and re-engineer both enterprise structure and behaviour. According to Loucopoulos and Kavakli [37], enterprise modelling is about describing, in some formal way, a social system with its agents, work roles, goals, responsibilities and the like. Earlier examples of techniques and formalisms for employing enterprise models are addressed in a requirements specification.

In the manufacturing domain, many researchers proposed a number of enterprise modelling approaches. Panetto and Molina [38] pointed out the need for holistic enterprise integration and interoperability frameworks, first analysing a number of perspectives and approaches and then discussing the challenges in designing collaborative networked manufacturing enterprises. However, it is only based on a review of the literature relevant to the domain, and offers a solution on a conceptual level. The ecosystem-inspired enterprise modelling framework will be presented in the next section as a set of theoretically robust practices for CMN enterprises. Reference architecture that works as a correspondence blueprint is crucial for any design project. CIMOSA is one of the wellknown enterprise architecture frameworks that targets manufacturing organisations; it provides a reference for enterprise requirements, structures activities alignment, and has been applied to networked enterprises [39]. In [40, 41] the authors proposed the ARCON modelling framework for collaborative networked organisations. ARCON is holistic, containing quite a large number of formal 
and informal modelling techniques, and a number of views of vertical and horizontal layers. However, it seems rather generic, and the literature does not seem to present a complete implementation for the suggested framework, nor any clear guidelines for why and when we should use a particular modelling tool in the real world. In another approach, Weston [42] and Masood, Weston and Rahimifard [43] have proposed a comprehensive model-driven manufacturing enterprise approach, which contains elements of structural and behavioural abstract modelling for both simulation and optimisation. This method is powerful, but it is only based on industrial experience and practices, lacking a grounding in complex systems theories. Nor does it propose any way of aligning models to the underlying information systems needed for manufacturing enterprises.

In a corresponding effort, international bodies have developed a number of standards relevant to EM. The goal was to standardise EM concepts, their representation, and the ways to implement EM systems in order to increase robustness, expressiveness, and interoperability. Organisations such as the International Organization for Standardization (ISO) and International Electrotechnical Commission (IEC) have developed standards that cover areas such as modelling and engineering, systems and subsystems, IT services, and infrastructures [44]. For instance, standards such as IEC/ISO 62264 for enterprise control systems integration and ISO 14258 for industrial automation systems provide concepts and rules for enterprise models. But the most important ones are ISO 19439:2006 [45] on enterprise modelling frameworks and ISO 19440:2007 [46] on enterprise modelling constructs. There are also several standards covering different levels of enterprise architecture and modelling, such as ISO 15704, ISO 15745, ISO 18629, ISO/IEC 15288, and ISO/IEC 15414 [44]. However, IEC/ISO 42010 (IEEE 1471) is another important standard as it identifies an enterprise architecture description metamodel. The Object Management Group (OMG) has a variety of standards important for modelling manufacturing enterprises, such as: Unified Modelling Language (UML), UML Profile for Business Process Definition, SysML, and UPDM. The Business Process Management Initiative (BPMI.org) organisation has introduced the Business Process Modelling Language (BPML) and the Business Process Query Language (BPQL) to enhance and standardise the development of business process management systems [44].

Table 1 below provides a summary and evaluates the relevant approaches which are considered academic research outputs.

Table 1: CMN current state of the art - literature analysis

\subsection{Ecosystem-Inspired EM Framework}

As was discussed in section four, CMN shares many of the characteristics of biological and ecological systems. It thus becomes a question of how to link ecosystem theory to EM, which can be answered through classifying the theory into a set of concepts and relationships, where each one of has its own settings and characteristics. The goal of EM practices and techniques is to externalise the knowledge about CMN, and to simulate the relationships or structures of business design that conform with ecosystem theory in order to understand its impact on the business. This assumes that each EM technique or practice can offer a particular quality to measure, test, analyse, or simulate some aspect of ecosystem theory. The following conceptual model (Figure 3) describes the relationship between the EM framework and ecosystem theory. 


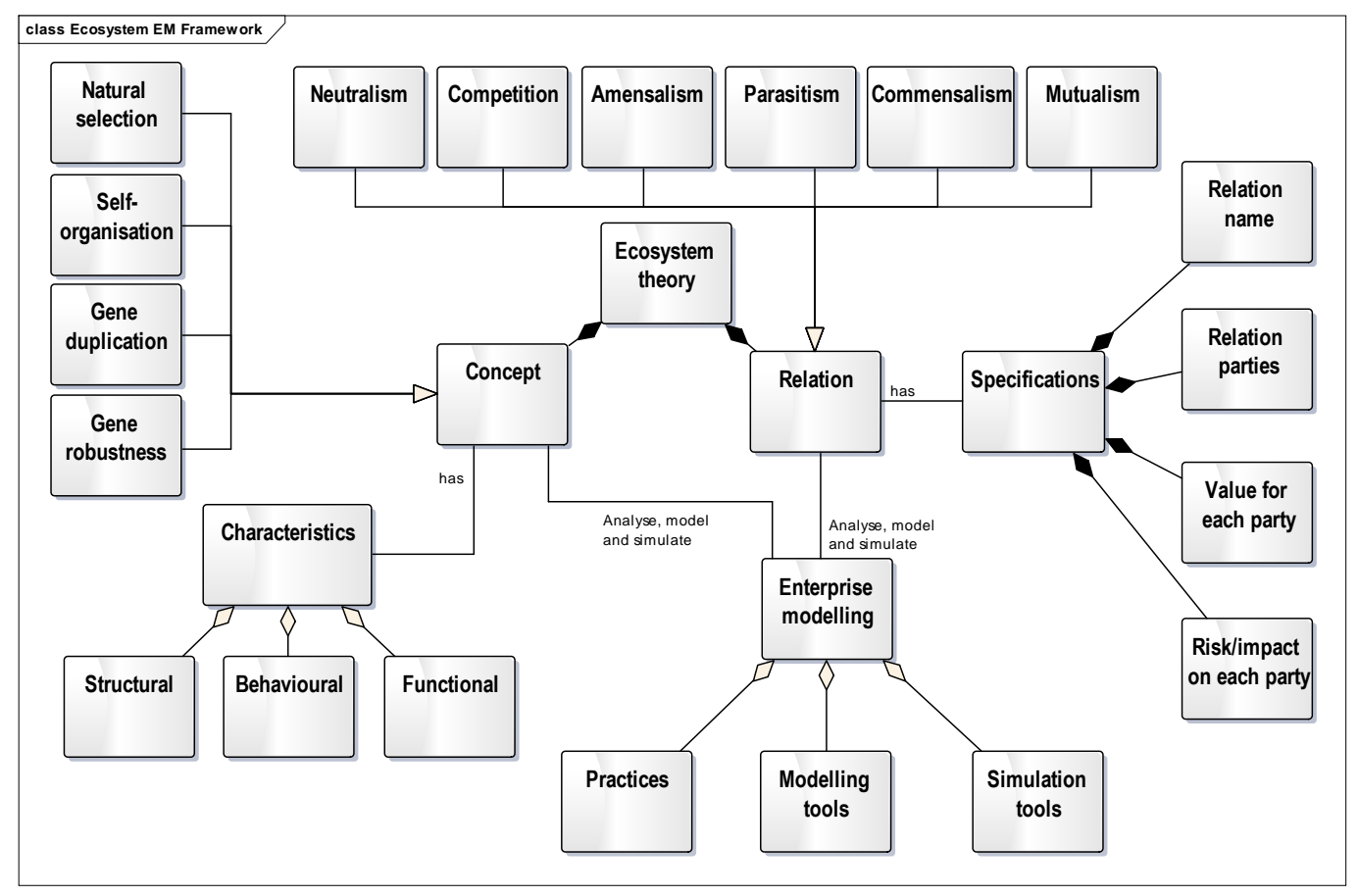

Fig. 3. The conceptual model of ecosystem-inspired EM framework

The framework designed in this paper can be considered a diagnostic framework, which helps to better understand:

- The relationships and communication patterns among manufacturing enterprises;

- the environmental and contextual constraints;

- the nature and direction of evolution;

- the tangible and intangible value of design-driven manufacturing activities; and

- how to build suitable infrastructure that is configurable and scalable.

This conceptualisation will lead to a framework that employs the features of an ecosystem by focusing on structural, behavioural, and functional aspects of the theory, paying special attention to the quality and performance of both the design and the operation. In an attempt to offer the maximum capability, the actual constructs of an ecosystem environment were mapped onto our suggested enterprise modelling framework in the following manner:

1. Symbiosis is a notion driven by capability and resources; manufacturing networks are interdependent in a complex service network. Practices of network structure modelling, resources and resource dependency modelling, value modelling, impact modelling, and causality modelling can be of help in analysing designs for a symbiosis network.

2. Natural selection is a market-driven process; manufacturing enterprises select their suppliers, partners, and alliances based on market availability. Market customers are able to choose between desired and undesired products the same way, and therefore the manufacturing 
company produces this product. Practices of market analysis, benchmarking, service level agreement, and operational modelling can be used to offer more insight about natural selection during design and operation.

3. Self-organisation is a goal-driven behaviour. Manufacturing enterprises will need to be agile and flexible in terms of fulfilling roles and responsibilities, enforcing rules and policies in order to achieve the desired goals and position themselves in the market. Goals, roles, responsibilities, policies, and rules can be modelled - and exceptional scenarios analysis, conflict analysis, compliance analysis employed - in order to govern the self-organisation process.

4. Gene duplication is concerned with sustainability. There is gene duplication if the enterprise wants to explore new potential to maintain or improve their market position, sustaining current production while trying to build a new business division that can explore new products or markets. If the company wants to minimise risk, research and development activities can be an alternative. Innovation models can capture the essential knowledge of this activity.

5. Gene robustness is concerned with value generation. A gene is robust only if it has the ability to survive during the evolutionary process, continuing to create the value that allows the enterprise to operate under different circumstances. Thus the value is robust while potential new capabilities are added to its offering, or introduced to the environment by another competitor. Portfolio management, benefit matrices, and ROI calculation are some potential practices to measure this process.

Figure 4 depicts an ontology model developed to bridge the gap between ecosystem theory and enterprise modelling techniques. This model will act as a mediator to facilitate selection of the EM techniques that enable practitioners to model, test, and simulate ecosystem features, relationships, and concepts, with the aim of finding the optimum settings that ensure value creation and the sustainability of the enterprise. Some tools can also be used for different features, depending on the purpose and focus of the analysis. These tools and approaches are detailed in table 2. 


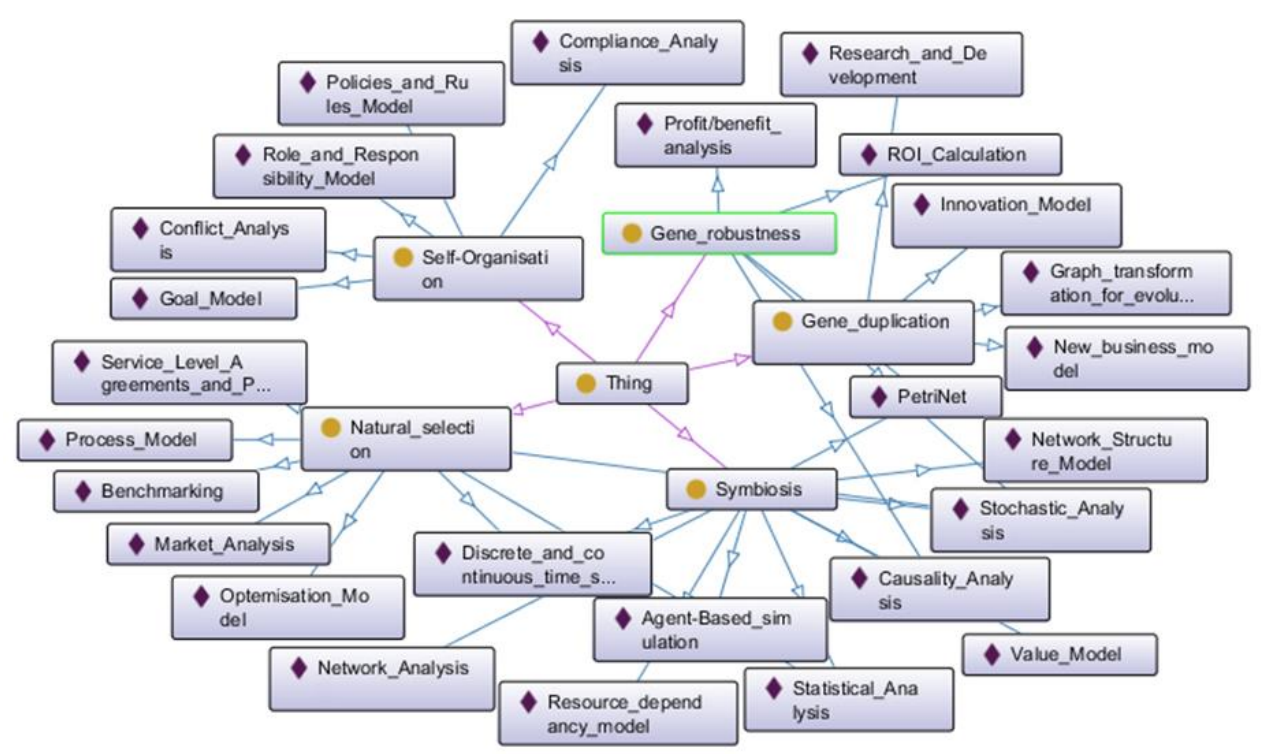

Fig. 4. Semantic map of ecosystem constructs associated to EM practices and tools.

Table 2: CMN best practices for EA modelling and simulation

\subsection{Domain Knowledge (The Metamodel)}

To efficiently use the techniques and tools suggested as part of the proposed framework, it is important to stress the need to increase the analyst's awareness of the surrounding environment where many factors play a role in influencing both CMN business design and operation. Three modelling levels were identified: The business ecosystem cues, which are mainly aspects external to the enterprise; the enterprise requirements, which identify the enterprise position and translate external aspects into a set of requirements that the enterprise needs to consider in its activities design; and the resources the enterprise needs to fulfil those requirements. The factors were grouped under set of high-level concepts, which means that concepts in the model can be broken down into sub-concepts or factors that have an impact on enterprise activities. The following model (Fig. 5) describes the main domain ontology where complex factors need to be considered for CMN analysis and design. 


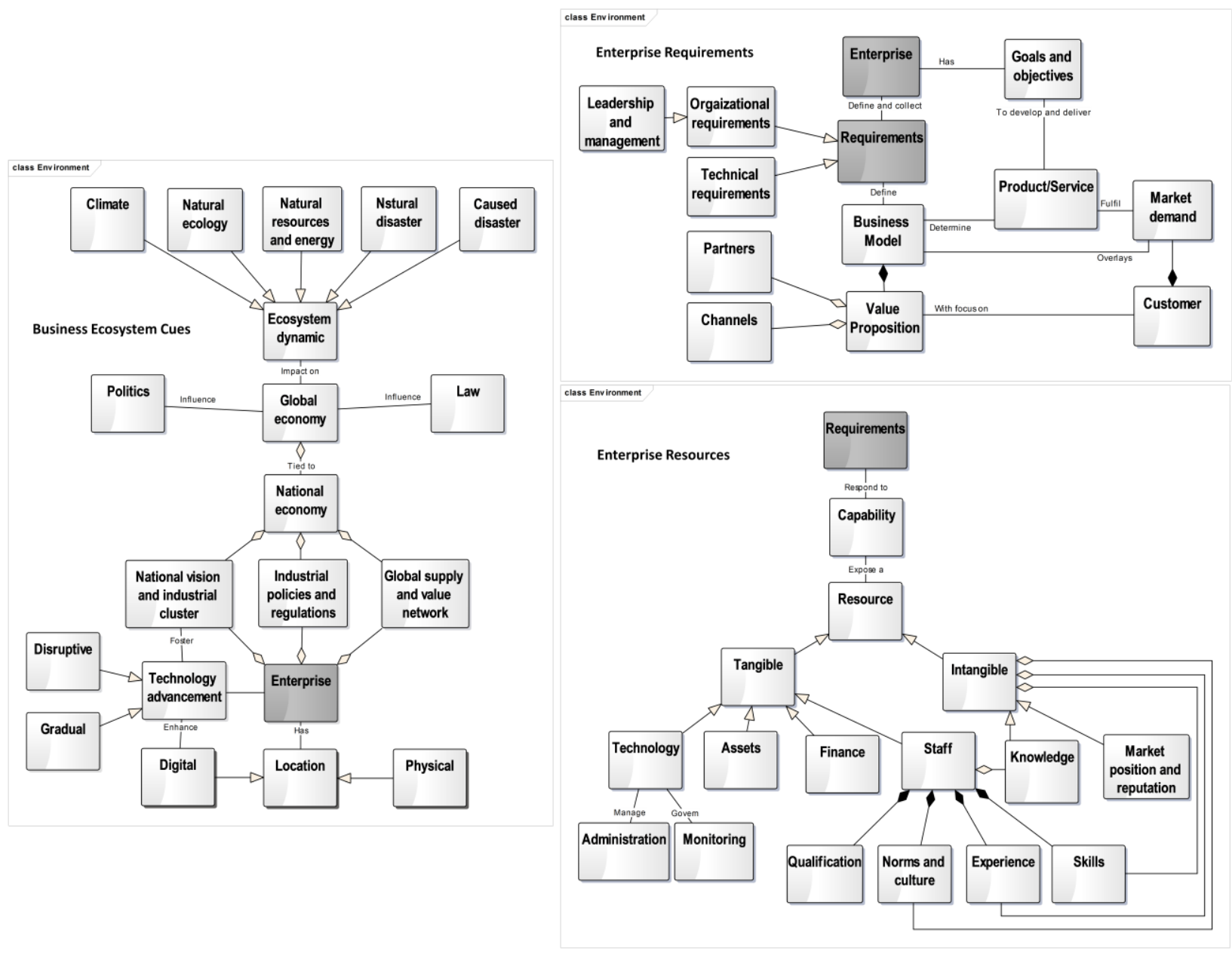

Fig. 5. CMN ecosystem metamodel.

\subsection{The Framework Details}

In order to deliver a practically successful modelling framework for CMN enterprises, enterprise planning must be supported using a set of modelling and simulation tools that facilitate understanding of the current and future requirements of both the market and of the business itself. This will allow the enterprise to reduce costs, increase the quality and efficiency of the manufacturing process, and achieve other objectives. Most importantly, it offers a valuable insight on their business and its environment, which will help in making the right operational and strategic decisions in future.

There are obvious feedbacks from the actual business activities in a manufacturing network to the modelling and design, as the enterprise continuously moves from the current "as-is" state to a designed "to-be" future state. Evaluating the current business activities based on performance matrices, and against the design objectives, will feed into rethinking and evolving the architecture and design models with the support of simulation and optimisation tools. In the same way, technology and information systems will feed back to business network activities in terms of potential new capabilities that can lead to innovation in the manufacturing business models. This feedback can also prove informative regarding the challenges and limitations that technology imposes on manufacturing business activities. Technology and information systems might also require new designs, 
modernisation, or optimisation; therefore, a feedback to modelling, design, and simulation is necessary for the technical design and architecture to consider new opportunities or threats.

The framework will be a model driven by business and IT development, which means that business models will be semantically aligned to IT models. However, the semantic is designed differently in different enterprise modelling or enterprise architecture frameworks, which can then be used as a reference architecture for the semantic alignment. The business models are also linked semantically to several alternative IT models, allowing different implementation choices that fit and respond to the criteria the enterprise has identified as best. The models also offer simulation and optimisation capabilities, and allow for the development of operation performance matrices.

Three aspects of the modelling platform are best used to implement such a framework. The first is concerned with modelling and simulation capabilities, employing business analysis and design models and IS/IT design and implementation models. Taking into account the available capabilities and motivational elements, the enterprise will select the optimum manufacturing network architecture and the settings that conform to business goals and objectives. The architecture will be fulfilled by several sub-models for strategy, operations, manufacturing, delivery, and customer services. Each existing pattern "model" will be combined with details about where and when the model should be implemented, and what constraints are associated with the model. Examples include motivational modelling, process modelling, network modelling, resources and capabilities modelling, organisational modelling, and rules and policies modelling. Furthermore, prediction analysis, dynamic simulation, sensitivity analysis, statistical analysis, and probability analysis provide businesssimulation capabilities. Once the suitable network and operation configuration has been selected, several IT/IS implementation models are linked to this business network configuration. They provide a variety of implementation choices, which the company can select based on which best fits their needs and the capabilities of the enterprise. These include service-oriented architecture, ubiquitous distributed architecture, cloud-based platforms, and mobile devices; IT modelling capabilities such as software modelling, system modelling, implementation modelling, deployment modelling, and network and infrastructure modelling; and IT simulation capabilities like validation and verification modelling, optimisation analysis, model consistency checking, stress analysis, and performance analysis.

The second aspect is concerned with interoperability amongst the modelling and simulation tools. This can be ensured through using ontology RDFs/OWL and semantic mapping of the modelling and simulation tool metamodels $[47,48]$. It is ensured that models with either the same or different levels of granularity are linked together semantically, a holistic design made easier by using and reusing model patterns in plug-and-play form that allows rapid searches and deployment, such as the patternbased techniques that have been used in modelling complex systems [49], e.g. strategy-to-operation, or operation-to-IS, or to machines.

Finally, the third aspect is concerned with adaptability and reconfigurability; a service-oriented platform that uses semantic services (WSDL-S) as suggested by Wang [12], and smart object UDDI [50]. The goal is to allow the platform to reconfigure models and components based on predefined adaptability rules, in order to plug in alternative $\mathrm{CMN}$ design or operation models once the contextual operation circumstances change. Businesses and systems in the runtime "under operation" also need to be analysed in order to feed new insight back into the design stage. The implementation and deployment of the models can feed experience back to the design aspect in two ways: Firstly, by 
recuperating simulation models by increasing analysts' experience with the implementation environment, its scenarios and conditions; and secondly by increasing knowledge and awareness about business and IT design, which will support better implementation for various business models with different emergent technologies. Optimisation models will help to optimise "as-is" operation through exploring new directions for "to-be" operation models. Data can be gathered using sensors, actuators, IoTs and machine-to-machine communication, or in the form of big data to enhance analysis and simulation capabilities. Reconfiguration decisions can benefit from ecosystem theory concepts and relations, setting up the platform to avoid unwanted configurations and adopt the optimum one. This aspect involves continuous assessment and evaluation, and the designer needs to update adaptability rules and constraints as necessary. Figure 6 illustrates the components of the suggested framework.

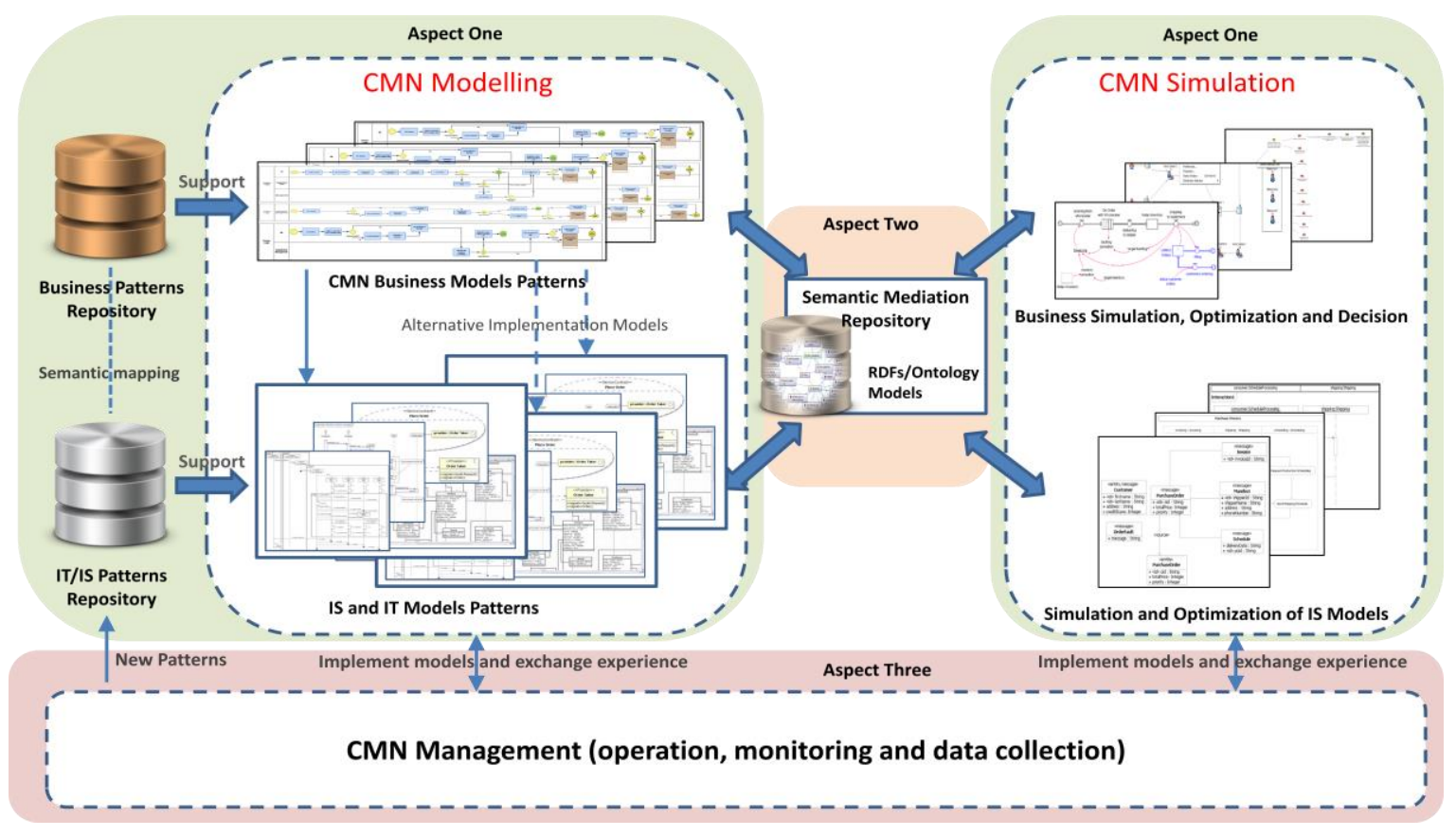

Fig. 6. Manufacturing enterprise modelling framework.

\subsection{Implementation Process for the Proposed Approach}

It is difficult to decide on the concrete steps for employing enterprise modelling, simulation, and analysis techniques. Firstly, every company has different goals and objectives for using them; for instance, some enterprises focus on particular problems, whereas others look for a holistic view of the current state "as-is" and some focus on the future state "to-be". Secondly, enterprises vary in their states, size, capabilities, scale, and complexity. However, the following guidelines provide a logical sequence for using the framework:

1. Strategic design, business goals and objectives, and the related KPIs.

2. Reasoning and simulation about business strategy, and assessing enterprise risks and opportunities. 
3. Designing network architecture, deciding the right topology of the collaborative network (for both services and products, and horizontal and vertical integration), and assessing all relations according to ecosystem theory relationship types.

4. Exploration of network design options, and the reasoning process to choose the optimum one.

5. Developing responsive business value chain and supply chain activities (including operations, rules, decisions, and constraints).

6. Operational simulation, assessing and evaluating performance and potential bottlenecks.

7. Designing software and information systems that respond to business processes.

8. IS/IT and systems simulation to verify, validate, and check performance.

9. Developing and deploying software applications and the underlying systems and technology, including any physical systems.

10. Continuous monitoring, requirements capturing, gap analysis, strategic alignment, and performance evaluation.

The logical steps to implement the proposed approach of enterprise modelling are described as an analysis and design loop in figure 7.

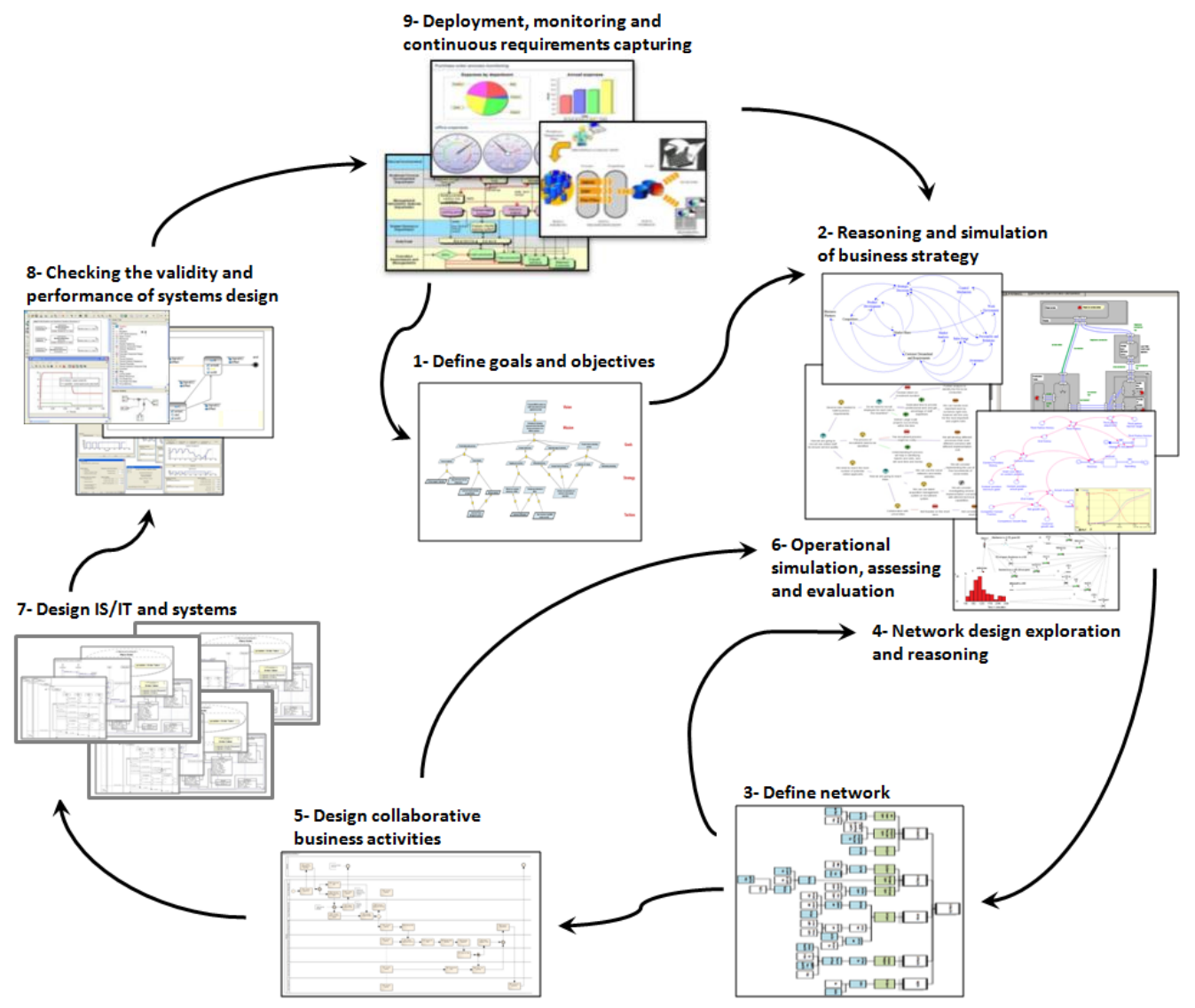

Fig. 7. Dynamic feedback loop as an implementation process. 


\section{Discussion and Conclusion}

Traditional manufacturing practices have been challenged to the degree that in order to remain competitive, enterprises have been forced to react to the patterns of change where dealing with past, present, and future decisions is concerned. This paper has discussed how CMN enterprises share some characteristics with natural ecosystems, and has developed framework notions that also benefit from ecosystem theory, which are then reflected by the framework architecture and enterprise modelling and simulation tools. It then proposes the analysis and design of internal and external aspects, and the use of enterprise modelling tools to align manufacturing strategy, operation, and information systems.

From an analysis and design point of view, simple and rigid analytics and design mechanisms are inefficient because the CMN environment is characterised by dynamism, nonlinearity, and complexity. In such a multi-scale and multi-level environment, knowledge that is often fragmented in different places and in different forms - both tacit and explicit - also depends on temporal, situational, and subjective perspectives. Such knowledge needs to be gathered, codified, and made explicit in such a manner that it can be subjected to analysis in a systematic and systemic way. Despite the fact that enterprise knowledge is recognised by many as the most important factor in successful business evolution, considerably less attention has been paid to the way this knowledge can be developed and used effectively in order to manage manufacturing enterprises towards their change in an evolving context. It can be assumed that a combination of design, simulation, and business practice is required for the successful use of enterprise knowledge based on the notions inspired by ecosystem theory. There are a number of concepts and relationships in ecosystem theory that need to be understood both individually and in relation to one other - in order to comprehend and analyse the complex and dynamic behaviour of the system. However, rather than focusing on what algorithms and techniques are about, the focus needs to be shifted onto how these algorithms and techniques are related to one another, and how they describe different aspects of a multi-scale system's collective behaviour.

This paper presents a novel enterprise modelling framework for analysing and designing evolvable and complex CMN enterprises. The framework proposes a diagnostic set of practices, models and simulation tools aimed at contributing towards building mature CMN enterprises that are able to understand and incorporate external changes within their inner manufacturing and business design. The framework is a hybrid one that aims to conceptualise a dynamic and complex world, through sense-making of the perceived issues within a modelling framework that is based on conceptual modelling for simulation, optimisation, and information systems implementations. The framework suggests a way, with instances, for ecosystem constructs to (a) simulate the quantitative preserved issues in order to improve managerial insight and decision-making, (b) model the CMN business environment, (c) consider the capability of ontology for knowledge mapping, and service-oriented systems for adaptation and self-configuration, and (d) utilise pattern-based techniques to enhance reusability and agility.

This paper attempts an exploration of how well-known enterprise practices, modelling, and simulations which have previously been used by researchers and practitioners can help in examining ecosystem theory concepts and relations. It argues that a selective number of these practices should work together in the suggested implementation structure to maximise benefit by allowing more maturity and agility in the analysis and design practices. Nevertheless, each particular case will require in-depth study to recognise the unique requirements and therefore to orchestrate the potential tools to achieve these particular requirements. These hypotheses were rooted in design science 
research approaches, where the research occurs in the real natural environment, and the designed artefacts are context-based, where it evolved within the timeframe [16]. There are three possible directions this work could take in future. The first would include more detailed classifications of ecosystem theory, investigating both the optimum settings and configurations for each enterprise in specific sets of circumstances, and what negative configurations the business should avoid. The second would use case studies to implement the framework and compare the differences in how analysis and design objectives vary from one manufacturing enterprise to another, allowing better decisions based on empirical findings to be made in future. The third would involve implementing the framework as an enterprise modelling tool that allows the design of CMN systems. Lessons can be learned from an early project, ComVantage [51, 52], investigating further the technical specifications of the suggested framework to develop a tool that has conceptual graphical notations, simulation, optimisation, and IS-development or integration capabilities.

Acknowledgment. The author thanks all reviewers who provided useful comments and feedback on an earlier version of this paper and the anonymous reviewers who offered their insightful comments through the review stage. 
Table 2: CMN current state of the art - literature analysis

\begin{tabular}{|c|c|c|c|c|c|c|c|c|}
\hline Authors and year & Journal & Perspective & Methodology & Focus & $\begin{array}{l}\text { Considers the } \\
\text { dynamic nature of } \\
\text { the CMN? }\end{array}$ & $\begin{array}{l}\text { Considering the } \\
\text { multi-layer of the } \\
\text { CMN? }\end{array}$ & $\begin{array}{l}\text { Suggest supportive } \\
\text { tools? }\end{array}$ & Theory driven? \\
\hline $\begin{array}{l}\text { Camarinha-Matos } \\
\text { and Afsarmanesh } \\
\text { [53]; Camarinha- } \\
\text { Matos, } \\
\text { Afsarmanesh, } \\
\text { Galeano and Molina } \\
\text { [41] }\end{array}$ & $\begin{array}{l}\text { Journal of } \\
\text { Intelligent } \\
\text { Manufacturing; } \\
\text { Computers \& } \\
\text { Industrial } \\
\text { Engineering }\end{array}$ & $\begin{array}{l}\text { Systems } \\
\text { engineering, } \\
\text { managerial } \\
\text { and Enterprise } \\
\text { Modelling }\end{array}$ & Guidelines & $\begin{array}{l}\text { Practical and } \\
\text { descriptive }\end{array}$ & Yes & Yes & Yes & $\begin{array}{l}\text { Yes. Multiple, but } \\
\text { not any in particular }\end{array}$ \\
\hline $\begin{array}{l}\text { Zaletelj, Sluga and } \\
\text { Butala [54] }\end{array}$ & $\begin{array}{l}\text { Concurrent } \\
\text { Engineering }\end{array}$ & $\begin{array}{l}\text { Enterprise } \\
\text { modelling }\end{array}$ & Yes-generic & Practical & Yes & Partly & Yes & No \\
\hline $\begin{array}{l}\text { Panetto and Molina } \\
\text { [38] }\end{array}$ & $\begin{array}{l}\text { Computers in } \\
\text { Industry }\end{array}$ & $\begin{array}{l}\text { Enterprise } \\
\text { systems } \\
\text { integration }\end{array}$ & No & Practical & $\begin{array}{l}\text { Yes }- \text { inner } \\
\text { enterprise only }\end{array}$ & Yes & Yes & No \\
\hline $\begin{array}{lr}\text { Weston } & {[42]} \\
\text { Masood, } & \text { Weston } \\
\text { and Rahimifard [43] }\end{array}$ & $\begin{array}{l}\text { Advances in } \\
\text { Decision Sciences }\end{array}$ & $\begin{array}{l}\text { Enterprise } \\
\text { modelling }\end{array}$ & Yes & Practical & Yes & Yes & Yes & No \\
\hline $\begin{array}{l}\text { Montreuil, Frayret } \\
\text { and D'Amours [7] }\end{array}$ & $\begin{array}{l}\text { Computers in } \\
\text { Industry }\end{array}$ & $\begin{array}{l}\text { Managerial } \\
\text { and enterprise } \\
\text { strategic } \\
\text { modelling }\end{array}$ & Yes & Practical & $\begin{array}{l}\text { Yes }- \text { inner } \\
\text { enterprise only }\end{array}$ & Yes & Yes & No \\
\hline Gadde [55] & $\begin{array}{l}\text { Industrial } \\
\text { Marketing } \\
\text { Management }\end{array}$ & Managerial & Guidelines & Descriptive & Yes & Partly & No & No \\
\hline $\begin{array}{l}\text { Kosanke } \\
\text { Et al, (1999) } \\
\text { CIMOSA }\end{array}$ & $\begin{array}{l}\text { Computers in } \\
\text { Industry }\end{array}$ & $\begin{array}{l}\text { Enterprise } \\
\text { modelling and } \\
\text { integration }\end{array}$ & Yes - generic & Practical & $\begin{array}{l}\text { Yes }- \text { inner } \\
\text { enterprise and no } \\
\text { particular practices } \\
\text { suggested }\end{array}$ & Partly & Yes & No \\
\hline
\end{tabular}


Table 2: CMN best practices for EA modelling and simulation

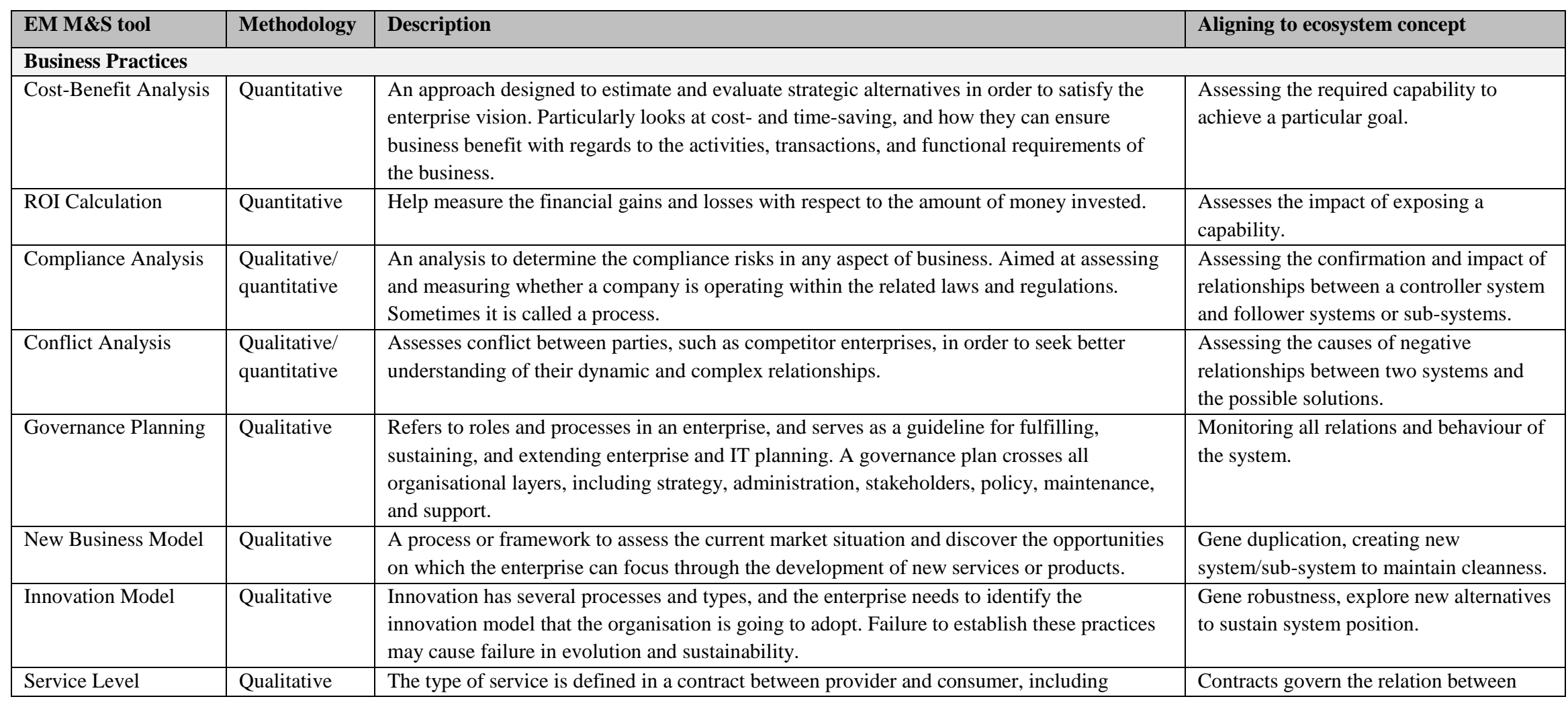




\begin{tabular}{|c|c|c|c|}
\hline Agreement & & $\begin{array}{l}\text { services, detention, details, roles and responsibilities, etc. Sometimes the term "SLA" refers } \\
\text { to the constricted performance and delivery time. }\end{array}$ & two systems. \\
\hline Benchmarking & $\begin{array}{l}\text { Qualitative/ } \\
\text { quantitative }\end{array}$ & $\begin{array}{l}\text { A method that helps to compare a company's business processes, practices, and performance } \\
\text { matrices to those of another company, or to the industrial standard practices adopted by some } \\
\text { particular companies. }\end{array}$ & $\begin{array}{l}\text { Cloning some feature of other sustained } \\
\text { systems. }\end{array}$ \\
\hline Market Analysis & $\begin{array}{l}\text { Qualitative/ } \\
\text { quantitative }\end{array}$ & $\begin{array}{l}\text { Studies the desirability and the dynamics of a specific market within a particular industry. It } \\
\text { contributes to industrial and organisation context analysis which offers valuable information } \\
\text { to strategic design. }\end{array}$ & $\begin{array}{l}\text { System contextual awareness and } \\
\text { explorations. }\end{array}$ \\
\hline $\begin{array}{l}\text { Strategic Business } \\
\text { Planning }\end{array}$ & Qualitative & $\begin{array}{l}\text { An organisation's practice for defining the strategic direction, by assessing and studying } \\
\text { several business aspects to support decision-making. Such decisions are relevant to adopting } \\
\text { tactical practices, allocating resources to pursue the strategy. It involves some elements of } \\
\text { directives for control, and guidelines for implementing and maintaining the strategy. It also } \\
\text { includes some other practices such as goal-setting and gap analysis. }\end{array}$ & $\begin{array}{l}\text { Self-organising, system setup, short-term } \\
\text { and long-term goals, and compatibility. }\end{array}$ \\
\hline Capacity Planning & $\begin{array}{l}\text { Qualitative/ } \\
\text { quantitative }\end{array}$ & $\begin{array}{l}\text { A process of defining the manufacturing and production capacity required by a particular } \\
\text { organisation in order to meet the dynamic change of its products and services. }\end{array}$ & $\begin{array}{l}\text { Natural selection, adopting features that } \\
\text { allow sustainability of the system and } \\
\text { checking their compatibility. }\end{array}$ \\
\hline \multicolumn{4}{|c|}{ Supportive Modelling Techniques } \\
\hline Value Modelling & $\begin{array}{l}\text { Qualitative/ } \\
\text { quantitative }\end{array}$ & \multicolumn{2}{|l|}{ Modelling and calculation of value flow between inter- and intra-manufacturing enterprise entities. } \\
\hline Goal Modelling & Qualitative & \multicolumn{2}{|c|}{$\begin{array}{l}\text { Capture, model, and decompose enterprise goals from high-level strategic goals, through operational goals, to ISs goals in an aligned and } \\
\text { systematic manner. Includes identification of KPIs for each particular goal. }\end{array}$} \\
\hline $\begin{array}{l}\text { Role and } \\
\text { Responsibility } \\
\text { Modelling }\end{array}$ & Qualitative & \multicolumn{2}{|c|}{$\begin{array}{l}\text { Models which roles and responsibilities can be fulfilled by organisations, units, or individual agents, and assigns particular responsibilities } \\
\text { to each. }\end{array}$} \\
\hline $\begin{array}{l}\text { Policies and Rules } \\
\text { Modelling }\end{array}$ & Qualitative & \multicolumn{2}{|c|}{ This includes structural and behavioural directives and constraints, and the way they enforce particular business objectives. } \\
\hline Process Modelling & Qualitative & \multicolumn{2}{|l|}{ Modelling of inter- and intra-business processes and aligning them to goals, rules, and roles. } \\
\hline Resources & Qualitative/ & \multicolumn{2}{|c|}{ Defines and models the resources that expose the particular capabilities required to fulfil business tasks and activities. This includes how } \\
\hline
\end{tabular}




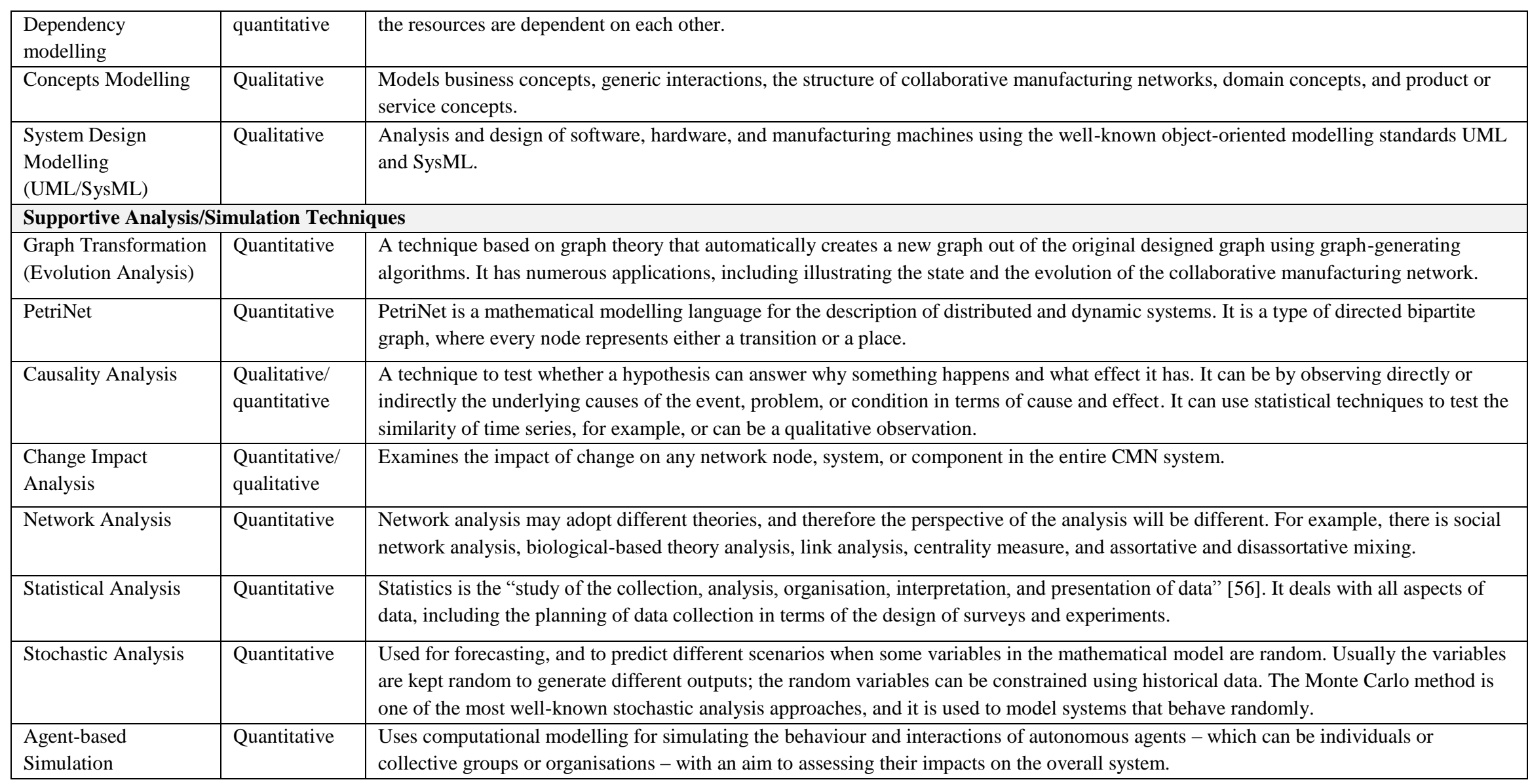




\begin{tabular}{|l|l|l|}
\hline $\begin{array}{l}\text { Discrete and } \\
\text { Continuous } \\
\text { Simulation }\end{array}$ & Quantitative & $\begin{array}{l}\text { Both are types of dynamic simulation. Continuous simulation sets up variables that are changing consistently in continuous manner and } \\
\text { not roughly from one state to another, with an infinite number of potential states. In a discrete simulation, the variables change only at a } \\
\text { countable number of points in time, or based on particular events that trigger the change in state. }\end{array}$ \\
\hline Genetic Algorithm & Quantitative & $\begin{array}{l}\text { An algorithm used for optimisation, based on Darwinian evolutionary theory. It uses a combination of random alteration and crossover } \\
\text { and selection procedures - natural selection - to breed or generate new and better models or solutions from an originally random starting } \\
\text { population or sample [57]. }\end{array}$ \\
\hline $\begin{array}{l}\text { Multi-objective } \\
\text { Optimisation }\end{array}$ & Quantitative & $\begin{array}{l}\text { Concerned with mathematical optimisation problems, where more than one objective function needs to be optimised or solved } \\
\text { simultaneously. A typical example of such a problems is increasing performance and reducing costs. It can use linear, nonlinear, discrete, } \\
\text { continuous, or subjective techniques. }\end{array}$ \\
\hline Data Analytics & $\begin{array}{l}\text { Quantitative/ } \\
\text { Reasoning/ } \\
\text { Logic }\end{array}$ & $\begin{array}{l}\text { In combination with other statistical or mathematical techniques, there are number of data analytics methods that have recently been } \\
\text { widely applied to dynamic and large data sets, used to analyse complex problems, and support decision-making. Examples include data } \\
\text { mining queries, process mining, machine learning, natural language processing, data reasoning, and logic and data visualisation. }\end{array}$ \\
\hline
\end{tabular}




\section{References}

[1] Z. Bi, L. Wang, Manufacturing Paradigm Shift Towards Better Sustainability, Cloud Manufacturing, Springer2013, pp. 99-119.

[2] D. Tapscott, Creating Value in the Network Economy, Ediciones Granica SA2000.

[3] N. Nohria, R. Gulati, What is the optimum amount of organizational slack?: A study of the relationship between slack and innovation in multinational firms, European Management Journal, 15 (1997) 603-611.

[4] P. Checkland, Soft systems methodology: a 30-year retrospective, (1999).

[5] J.D. Sterman, Business Dynamics: Systems Thinking and Modeling for a Complex World, Irwin/McGraw-Hill Boston2000.

[6] M. Jahangirian, T. Eldabi, A. Naseer, L.K. Stergioulas, T. Young, Simulation in manufacturing and business: A review, European Journal of Operational Research, 203 (2010) 1-13.

[7] B. Montreuil, J.-M. Frayret, S. D'Amours, A strategic framework for networked manufacturing, Computers in industry, 42 (2000) 299-317.

[8] S. Lee, G. Park, B. Yoon, J. Park, Open innovation in SMEs-An intermediated network model, Research policy, 39 (2010) 290-300.

[9] Y. Zhang, M. Gregory, Y. Shi, Global engineering networks: the integrating framework and key patterns, Proceedings of the Institution of Mechanical Engineers, Part B: Journal of Engineering Manufacture, 221 (2007) 1269-1283.

[10] Y. Zhang, D. Fleet, Y. Shi, J.S. Srai, M. Gregory, Network integration for international mergers and acquisitions, European Journal of International Management, 4 (2010) 56-78.

[11] Y. Zhang, M. Gregory, Managing global network operations along the engineering value chain, International Journal of Operations \& Production Management, 31 (2011) 736-764.

[12] Q. Wang, Networked collaborative manufacturing mode based on manufacturing services, intelligent information technology application, 2008. IITA'08. Second International Symposium on, IEEE, 2008, pp. 218-222.

[13] V. Modrák, V. Moskvich, Impacts of RFID implementation on cost structure in networked manufacturing, International Journal of Production Research, 50 (2012) 3847-3859.

[14] D.T. Tohmatsu, The challenge of complexity in global manufacturing: Critical trends in supply chain management, Deloitte Touche Tohmatsu Global Benchmark Study Report, (2003).

[15] K. Peffers, T. Tuunanen, M.A. Rothenberger, S. Chatterjee, A design science research methodology for information systems research, Journal of management information systems, 24 (2007) 45-77.

[16] R. O'Keefe, Design Science, the design of systems and Operational Research: back to the future [quest], Journal of the Operational Research Society, 65 (2013) 673-684.

[17] W. Kuechler, V. Vaishnavi, A framework for theory development in design science research: multiple perspectives, Journal of the Association for Information systems, 13 (2012) 395-423.

[18] M.Q. Patton, Qualitative Evaluation and Research Methods, SAGE Publications, inc1990.

[19] S.T. March, G.F. Smith, Design and natural science research on information technology, Decision support systems, 15 (1995) 251-266.

[20] S.P. Hubbell, The Unified Neutral Theory of Biodiversity and Biogeography (MPB-32), Princeton University Press2001.

[21] D. Alonso, R.S. Etienne, A.J. McKane, The merits of neutral theory, Trends in ecology \& evolution, 21 (2006) 451-457.

[22] J. Bosch, From software product lines to software ecosystems, Proceedings of the 13th International Software Product Line Conference, Carnegie Mellon University, 2009, pp. 111-119.

[23] L. Yu, S. Ramaswamy, Software and biological evolvability: a comparison using key properties, Software Evolvability, 2006. SE'06. Second International IEEE Workshop on, IEEE, 2006, pp. 82-88.

[24] L. Yu, S. Ramaswamy, J. Bush, Software evolvability: an ecosystem point of view, Software Evolvability, 2007 Third International IEEE Workshop On, IEEE, 2007, pp. 75-80.

[25] R. Fidel, Human Information Interaction: an Ecological Approach to Information Behavior, MIT Press2012.

[26] G. Briscoe, P. De Wilde, Digital ecosystems: evolving service-orientated architectures, Proceedings of the 1st International Conference on Bio Inspired Models of Network, Information and Computing Systems, ACM 17, 2006, pp. 17.

[27] G. Briscoe, S. Sadedin, G. Paperin, Biology of applied digital ecosystems, Digital EcoSystems and Technologies Conference, 2007. DEST'07. Inaugural IEEE-IES, IEEE, 2007, pp. 458-463.

[28] G. Briscoe, Complex adaptive digital ecosystems, Proceedings of the International Conference on Management of Emergent Digital EcoSystems, ACM, 2010, pp. 39-46.

[29] H.H. Horaguchi, Collective Knowledge Management: Foundations of International Business in the Age of Intellectual Capitalism, Edward Elgar Publishing2014.

[30] P. Checkland, Systems Thinking. Rethinking Management Information Systems: An Interdisciplinary Perspective. W Currie and R. Galliers, Oxford, Oxford University Press, 1999.

[31] M. Jarke, P. Loucopoulos, K. Lyytinen, J. Mylopoulos, W. Robinson, The brave new world of design requirements, Information Systems, 36 (2011) 992-1008.

[32] E. Mumford, The story of socio-technical design: Reflections on its successes, failures and potential, Information Systems Journal, 16 (2006) 317-342.

[33] M. Onori, D. Semere, B. Lindberg, Evolvable systems: an approach to self-X production, International Journal of Computer Integrated Manufacturing, 24 (2011) 506-516. 
[34] J. Lee, M. Ghaffari, S. Elmeligy, Self-maintenance and engineering immune systems: towards smarter machines and manufacturing systems, Annual Reviews in Control, 35 (2011) 111-122.

[35] J.R. Jiao, X. You, A. Kumar, An agent-based framework for collaborative negotiation in the global manufacturing supply chain network, Robotics and Computer-Integrated Manufacturing, 22 (2006) 239-255.

[36] F.B. Vernadat, Enterprise Modeling and Integration: Principles and Applications, Chapman \& Hall London 1996.

[37] P. Loucopoulos, E. Kavakli, Enterprise modelling and the teleological approach to requirements engineering, International Journal of Cooperative Information Systems, 4 (1995) 45-79.

[38] H. Panetto, A. Molina, Enterprise integration and interoperability in manufacturing systems: Trends and issues, Computers in industry, 59 (2008) 641-646.

[39] K. Kosanke, F. Vernadat, M. Zelm, CIMOSA: enterprise engineering and integration, Computers in industry, 40 (1999) 83-97.

[40] L.M. Camarinha-Matos, Collaborative networked organizations: status and trends in manufacturing, Annual Reviews in Control, 33 (2009) 199-208.

[41] L.M. Camarinha-Matos, H. Afsarmanesh, N. Galeano, A. Molina, Collaborative networked organizations-Concepts and practice in manufacturing enterprises, Computers \& Industrial Engineering, 57 (2009) 46-60.

[42] R.H. Weston, Model driven integrated decision-Making in manufacturing enterprises, Advances in Decision Sciences, $2012(2012)$.

[43] T. Masood, R. Weston, A. Rahimifard, A model-driven approach to enabling change capability in SMEs, The International Journal of Advanced Manufacturing Technology, 69 (2013) 805-821.

[44] D. Minoli, Enterprise Architecture A to Z: Frameworks, Business Process Modeling, SOA, and Infrastructure Technology, CRC Press2008.

[45] I.O.f.S. ISO, ISO 19439:2006: Enterprise Integration - Framework for Enterprise Modelling, Geneva, 2006.

[46] I.O.f.S. ISO, ISO 19440:2007: Enterprise Integration - Constructs for Enterprise Modelling, Geneva, 2007.

[47] A. Fayoumi, P. Loucopoulos, A. Fayyoumi, Hybrid enterprise modelling: integrating modelling mechanisms for socioTechnical systems analysis and design, Journal of Software Engineering and Applications, 2014 (2013).

[48] D. Karagiannis, H.-G. Fill, P. Höfferer, M. Nemetz, Metamodeling: Some application areas in information systems, Springer2008.

[49] R.S. Kalawsky, D. Joannou, Y. Tian, A. Fayoumi, Using architecture patterns to architect and analyze systems of systems, Procedia Computer Science, 16 (2013) 283-292.

[50] Y. Zhang, G.Q. Huang, T. Qu, S. Sun, Real-Time work-in-Progress management for ubiquitous manufacturing Environment, Cloud Manufacturing, Springer2013, pp. 193-216.

[51] T. Münch, R. Buchmann, J. Pfeffer, P. Ortiz, C. Christl, J. Hladik, J. Ziegler, O. Lazaro, D. Karagiannis, L. Urbas, An innovative virtual enterprise approach to agile micro and SME-based collaboration networks, Collaborative Systems for Reindustrialization, Springer2013, pp. 121-128.

[52] J. Ziegler, M. Graube, J. Pfeffer, L. Urbas, Beyond app-chaining: mobile app orchestration for efficient model driven software generation, Emerging Technologies \& Factory Automation (ETFA), 2012 IEEE 17th Conference On, IEEE, 2012, pp. 1-8.

[53] L.M. Camarinha-Matos, H. Afsarmanesh, A comprehensive modeling framework for collaborative networked organizations, Journal of Intelligent Manufacturing, 18 (2007) 529-542.

[54] V. Zaletelj, A. Sluga, P. Butala, A conceptual framework for the collaborative modeling of networked manufacturing systems, Concurrent Engineering, 16 (2008) 103-114.

[55] L.-E. Gadde, Distribution network dynamics and the consequences for intermediaries, Industrial Marketing Management, 43 (2014) 622-629.

[56] J.W. Kuzma, S.E. Bohnenblust, Basic statistics for the health sciences, McGraw-Hill2005.

[57] M.B. Wall, A Genetic Algorithm for Resource-constrained Scheduling, Massachusetts Institute of Technology, 1996. 